\title{
Assessment on the Implementation of Special Program in Sports and Student-Athletes Performance in Sports Competition
}

\author{
Rayvin D. Pestano ${ }^{1, *}$, Florante P. Ibarra ${ }^{2}$ \\ ${ }^{1}$ Institute of Sports, Physical Education and Recreation, College of Education, Central Luzon State University, Science City of Munoz, \\ 3119, Nueva Ecija, Philippines \\ ${ }^{2}$ Department of Advance Studies in Education, College of Education, Central Luzon State University, Science City of Munoz, 3119, \\ Nueva Ecija, Philippines \\ *Corresponding Author: rayvin.pestano@clsu2.edu.ph, fpibarra@clsu.edu.ph
}

Received April 18, 2021; Revised May 31, 2021; Accepted June 25, 2021

\section{Cite This Paper in the following Citation Styles}

(a): [1] Rayvin D. Pestano, Florante P. Ibarra , "Assessment on the Implementation of Special Program in Sports and Student-Athletes Performance in Sports Competition," International Journal of Human Movement and Sports Sciences, Vol. 9, No. 4, pp. 791 - 796, 2021. DOI: 10.13189/saj.2021.090425.

(b): Rayvin D. Pestano, Florante P. Ibarra (2021). Assessment on the Implementation of Special Program in Sports and Student-Athletes Performance in Sports Competition. International Journal of Human Movement and Sports Sciences, 9(4), 791 - 796. DOI: 10.13189/saj.2021.090425.

Copyright@2021 by authors, all rights reserved. Authors agree that this article remains permanently open access under the terms of the Creative Commons Attribution License 4.0 International License

\begin{abstract}
Purpose: This study aims to evaluate the implementation of a Special Program in Sports (SPS) in eight secondary school implementers in the province of Nueva Ecija, Philippines. Likewise, student-athlete performance in sports competitions in the division level, regional level, and national level athletic meet was also assessed. Methodology: Using a descriptive correlational research design, 59 teacher/coach/trainer handling specialization subjects in SPS program participated in the study. Quantitative data were gathered using a self-made questionnaire as the main instrument. Findings: Respondents perceived evaluation on the implementation of a special program in sports were highly sufficient in the areas of the planned curriculum for sports, admission and retention policies, student support, manpower resources, and instructional resources and moderately sufficient in the areas of school sports facilities. Furthermore, student-athletes performance at the division level was found to be very satisfactory, while unsatisfactory at the regional and national level sports competition. Human resources and school sports facilities were found to have significant relationship with student-athletes performance in sports competition. Contribution and Recommendation: Therefore, it is highly recommended that schools that implement special program in sports should provide adequate sports facilities, equipment, and
\end{abstract}

competent coaches as these more likely to have great impact on athletes' performance.

Keywords Implementation of Special Program in Sports, Student-Athletes Performance, Sports Competition

\section{Introduction}

Special program in sports in the Philippine archipelago offers significant development in sports and education serving as platform to nurturing athletic and sports skills among students. The SPS program curriculum design provides a four-year secondary curriculum guided by $\mathrm{K}$ to 12 Basic Education Program patterned after that of a regular high school with specialization in sports in individual, dual, and team sports. Athletic oval, gymnasium and swimming pool are essential mandatory facilities for a school to qualify in offering this program. Furthermore, Specialist (specialization teacher) teachers/coaches/trainers that possess bachelor's degree with specialization in Physical Education/Sports or any relevant degree in sports and human movement exercise are qualified to handle this program. The program was envisioned primarily to address the needs of talented Junior High School students both in public and private 
institutions regardless of their ability and level in different amateur sports discipline, to establish and create a pool of athletes who will be trained to compete in regional, national, and international sports competition [1]. Thus, it is, therefore, necessary to evaluate its degree of implementation that would center on administrative support, facilities, human power, and instructional resources which may serve as influencing elements to student performance. The diversity of factors that contribute to the success or failure of a specific program lies in the existing facilities provided by the host institution [2]; [3]. As an educational institution, it has to deliver the products and services necessary to achieve the outcomes it intends to produce [4]

Though the implementation of Special Program in Sports (SPS) in the country had been put into practice for quite some time, there had been no previous chronicled assessment on its extent of implementation to further evaluate the realization of its goals and objectives. Similarly, there had also been insufficient empirical evidence that supports how the extent of its implementation could contribute to student-athletes performance in amateur sports competition as stipulated in the DepEd. Guidelines [1]

For over a decade, a special program in sports has been implemented in the province of Nueva Ecija, students output in the division athletic meet has a very satisfactory result, while on a regional athletic meet and national athletic meet, its result has been remarkably alarming. A constant decline in student performance under the SPS program has been likewise observed.

Student-athletes' performance could be measured through actual results obtained by an athlete in an amateur competition. These actual results could serve as a basis for improving athletes as well as school sports performance. Limited studies show that athletes' performance is determined by the athlete's technical, tactical, physiological, and psychological / sociological characteristics [5] and coaches' coaching style and competencies [6]

\subsection{Problem Statement}

Since the launch of the implementation of a special program in sports in the year 2000, there had been no studies conducted to evaluate the program. One of the researchers was a previous teacher of SPS. With the common notion that students learn best when they are provided with ample facilities and equipment would be the underlying contention of this research study. Given such premise, SPS evaluation is indeed necessary to further improve the program and its implementation.

\subsection{Research Objectives}

(a) To determine the extent of implementation of a special program in sports as perceived by the respondents in terms of the planned curriculum, admission policy, retention policy, student support, sports facilities, manpower resources, and instructional resources.

(b) To determine student-athletes performance in sports competitions in the division, regional, and national athletic meets.

(c) To find out whether the extent of implementation of a special program in sports has a significant relationship with student-athletes performance.

\subsection{Research Hypothesis}

There is statistically no significant relationship between the implementation of special program in sports and student-athletes performance.

\subsection{Research Terminology}

(a) Special Program in Sports- A special curriculum program that offers a four-year secondary curriculum patterned in a regular high school with specialization in individual, dual and team sports.

(b) Division Level- Inter-school amateur sports competition both in elementary and secondary within certain city or province. Winning athletes in the division level are qualified to compete in regional level sports competition.

(c) Regional Level- Region wide level of amateur sports competition composed of winning athletes from different provinces, cities and divisions to qualify for national level competition.

(d) National Level- Highest level of amateur sports competition for elementary and secondary student-athletes in the Philippines.

(e) Specialist- Refers to a teacher/coach/trainer that handles sports specialization classes.

(f) SPS Student-Athlete- is a student enrolled in special program in sports.

\section{Literature Review}

Bustamante [7] conducted a study on the implementation of sports program in Region II, Philippines. The aim of the study was to examine the state of implementation in the sphere of physical culture and sports, and develop methodological foundations of sports and health services. Upon a comprehensive study of the philosophical, psychological-pedagogical, and methodological literate, the content analysis of the main category "implementing sports" had been conducted. The content analysis summarizes the ideas of foreign researchers on the sphere of "implementing sports". The authors of the research proposed a developed technique of a special course "Sports and Health Services" for coaches, organizers and specialist working in the sphere of physical 
culture and sports.

Mercado [8] assessed the sports development program curriculum given in schools of physical education in Bicol State University, Philippines. A total of 23 physical education and sports teachers participated in the study. The participants were given four weeks to assess the courses on the evaluation of form according to curricular programs in sports. Results of the study showed that courses included in the curriculum such as applied skills in sports and sports history were predictors of academic performance.

Onofre and Marquez [9] carried a study on the physical education sports program in the Philippines linking it to the collective desirability of its student-athletes. Utilizing a descriptive correlational study, a total of 123 student-athletes served as respondents. A survey instrument was administered to determine how curricular design would fit the needs of student-athletes individually and collectively. Findings revealed that individual sports courses needed to be re-evaluated with regards to skills scopes as well as content-based problems.

Hardman [10] evaluated the sports curriculum in selected sports institution in London to look further into contents included in the sports program. The aim of the study was to assess which curses would be beneficial to student-athletes that could compliment their academic undertakings. Results found out that sole courses that enhanced their practical skills were sports courses.

\section{Materials and Methods}

\subsection{Research Design}

This study utilized a Quantitative Descriptive and Correlation design to identify, analyze, and describe the extent of implementation of Special Program in Sports (SPS) concerning student-athletes performance in the Province of Nueva Ecija, Philippines. According to Bernard [11], research design serves as a blue print, or outline for conducting a study in such a way that maximum control will be exercised over factors that could interfere with the validity of research results. The research design is an overall plan for obtaining answers to the research question guiding the study.

\subsection{Research Subject}

The study population consisted of 59 teachers/coaches/trainers participated in this research using total population sampling to provide complete and accurate information. Bernard [11] describes total population sampling which involves examining the whole population that has a particular set of characteristics.

\subsection{Research Instrument}

Using an online questionnaire through Google form, this was sent to school principals of each institution to be filled out by purposively chosen teacher/coach/trainer respondents. The instrument used was a questionnaire on the evaluation of the implementation of a special program in sports which focused on planned curriculum, admission/ extension policies, student support, school's sports facilities, manpower resources, and instructional using a Likert rating scale 4- Highly Sufficient, 3Moderately Sufficient, 2 - Less Sufficient and 1 Insufficient. Furthermore, to determine the student-athletes performance, amateur sports competition data from the Department of Education for three consecutive years served as a reference using the Fibonacci numerical point system.

Table 1. Point System

\begin{tabular}{|c|c|}
\hline Point System & Description \\
\hline $75-100$ & Very Satisfactory \\
\hline $50-74$ & Satisfactory \\
\hline $25-49$ & Needs Improvement \\
\hline $0-24$ & Poor \\
\hline
\end{tabular}

\subsection{Data Analysis}

This study utilized SPSS statistical program version 16.0 to process the data. Frequency counts, percentage, mean and Pearson correlation were also used to examine significant relationships of the variables being examined.

\section{Result and Discussion}

Based on the results of the study on the extent of implementation of a special program in sports and student-athletes' performances, the following results are gathered:

Table 2. Implementation of Special Program in Sports

\begin{tabular}{|c|c|c|}
\hline $\begin{array}{c}\text { Implementation of Special } \\
\text { Program in Sports }\end{array}$ & Mean & Description \\
\hline Planned Curriculum for Sports & 3.24 & $\begin{array}{c}\text { Highly } \\
\text { Sufficient }\end{array}$ \\
\hline $\begin{array}{c}\text { Admission/Retention Policies } \\
\text { for Sports }\end{array}$ & 3.40 & $\begin{array}{c}\text { Highly } \\
\text { Sufficient }\end{array}$ \\
\hline Student Support & 2.36 & $\begin{array}{c}\text { Highly } \\
\text { Sufficient }\end{array}$ \\
\hline School Sports Facilities & 3.09 & $\begin{array}{c}\text { Moderately } \\
\text { Sufficient }\end{array}$ \\
\hline Manpower Resources & 3.28 & $\begin{array}{c}\text { Highly } \\
\text { Sufficient }\end{array}$ \\
\hline Instructional Resources & 3.40 & $\begin{array}{c}\text { Highly } \\
\text { Sufficient }\end{array}$ \\
\hline Overall Weighted Mean & 3.25 & $\begin{array}{c}\text { Highly } \\
\text { Sufficient }\end{array}$ \\
\hline
\end{tabular}

Result shows that respondent's perception in the implementation of a special program in sports was found to be Highly Sufficient in the areas of the planned 
curriculum, admission/retention policies, student support and manpower resources, and Moderately Sufficient in terms of school sports facilities and instructional resources. Respondent's perception in the implementation of a special program in sports in terms of the planned curriculum was described as Highly Sufficient. The findings most likely implied that there had been adequate learning competencies in individual, dual, and team sports. Results suggested that expertise in a specific field of sports specialization was a significant factor to transfer explicit knowledge and skills to the student. Toktas and Bas [12], found out that teaching specific sports involved establishing teacher identity as sources of knowledge and skills that every studentathlete needs.

Findings showed that the admission/retention policy for sports was highly sufficient. Respondents perceived that there had been adequate standard for screening, rules on retention based on students' academic performance, and provisions for acceptance and guidelines in choosing a sport. Gencer and Öztürks [13], emphasized that Sports programs designed with vivid implementing regulations would lead to positive outcomes in sports performance among student-athletes. While coaches serving as models and channels to student-athletes ${ }^{\text {ee }}$ sports developments, their actions and expectations remained on the admissible process of gradual yet intensive training of their student-athletes.

Results on student support implied that respondents tended to perceive sufficient provisions in the implementation of special program in sports. Conversely, it was suggested that there must be a safety measure given to the athletes, adequate learning delivery for sports competition, and remedial and mentoring in academic subjects. More so, coaches are likely to perceive that there are moderately sufficient provisions of uniforms for athletes while meals and allowance. Moens and Federicis
[14], argue that schools offering sports program tended to give priority to safety measures among their athletes. First aid training was incorporated in different sports preparation to give student-athletes as well as coaches adequate knowledge on first aid techniques combined with the actual medical attention and demonstration. Respondents more likely perceived that the implementation of a special program in sports on school sports facilities tended to be moderately sufficient. This implies that there is ample equipment used in team sports most specifically in ball games, individual and dual sports, covered courts, and track oval events.

Considering the manpower resources, results most likely suggested that there is adequate manpower in the implementation of a special program in sports. Respondents perceived that there is a highly sufficient qualification for handling sports programs such as track records, knowledge, and skills of teachers in various sports programs. On the other hand, respondents suggested that there is a moderately sufficient linkage to Non-Governmental organizations (NGO's), Government Offices (GO's) for funds as well as budgetary allocation to sustain the sports program. This suggests that coaches and sports heads should have higher standards and must be equipped with sufficient skills in sports as compared to those handling general physical education classroom teaching.

In instructional resources, findings revealed that respondents perceived moderately sufficient availability of textbooks, modules, and instructional videos as well as teaching expertise which are imperative in the teaching and learning process. Teachers need to examine the materials currently used in their health and physical education program to ensure that the materials will assist students to meet the Standards [15].

Table 3. Student-Athletes Performance in Individual, Dual, and Team Sports for the Last Three Years

\begin{tabular}{|c|c|c|c|c|c|c|c|}
\hline Events & Gold & Silver & Bronze & Participant & Total & $\begin{array}{c}\text { Fibonacci Weighted } \\
\text { Point System }\end{array}$ & Description \\
\hline \multicolumn{8}{|l|}{ Individual Sports } \\
\hline Division Level & 72 & 21 & 4 & 16 & 113 & 87 & VS \\
\hline Regional Level & 16 & 15 & 8 & 48 & 87 & 29 & \\
\hline National Level & 14 & 1 & 0 & 39 & 4 & 5 & \\
\hline \multicolumn{8}{|l|}{ Dual Sports } \\
\hline Division Level & 30 & 11 & 3 & 11 & 54 & 38 & NI \\
\hline Regional Level & 6 & 3 & 3 & 33 & 45 & 9 & US \\
\hline National Level & 2 & 2 & 0 & 29 & 33 & 3 & US \\
\hline \multicolumn{8}{|l|}{ Team Sports } \\
\hline Division Level & 59 & 11 & 3 & 17 & 92 & 62 & S \\
\hline Regional Level & 4 & 6 & 12 & 51 & 73 & 28 & US \\
\hline National Level & 1 & 2 & 0 & 40 & 42 & 2 & US \\
\hline
\end{tabular}


Table 3 shows the student athletes' performance for the last three years. It can be noticed in division level in terms of individual sports, records show 72 gold, 21 silver and 4 bronze with a total of 87pts described as Very Satisfactory Performance. In terms of dual sports, it can be noticed in the records that there are 30 gold, 11 silver, 3 bronze with a sum of 38pts described as Needs Improvement Performance. As to team sports, records presented that there are 59 gold, 11 silver, and 3 bronze with a total of 67pts described as Satisfactory Performance. In terms of regional level in individual sports, records show there are 16 gold, 15 silver, and 8 bronze with a sum of 29pts described as Needs Improvement Performance. With regards to dual spots, records show 6 gold, 3 silver, and 3 bronze with a total of 9pts described as Unsatisfactory Performance. As to team sports, data show 4 gold, 6 silver, and 12 bronze with a total of 28pts described as Satisfactory Performance. In terms of regional level in individual sports, records show 16 gold, 15 silver, and 8 bronze with a sum of 29pts described as Needs Improvement Performance. With regards to dual, it can be seen that there are 6 gold, 3 silver, and 3 bronze with a total of 9pts described as Unsatisfactory Performance. As to team sports, coaches received 4 gold, 6 silver, and 12 bronze with a total of 28pts described as Satisfactory Performance. As to National level in individual sports, dual sports, and team sports, their performance got a description of Unsatisfactory Performance since accumulated points in national level in each sports category are less than 24pts.

Student-athletes performance in individual, dual, and team sports competition illustrates that as the level of competition becomes higher, their performance becomes lower. Winning at a higher level of competition becomes harder and that instance is normal since all athletes competing are already winners in such events.

Table 4. Relationship between Implementation of Special Program in Sports and Student-Athletes Performance

\begin{tabular}{|c|c|c|c|}
\hline \multirow{2}{*}{$\begin{array}{c}\text { Implementation of } \\
\text { Special Program in Sports }\end{array}$} & \multicolumn{3}{|c|}{ Student Athletes Performance } \\
\cline { 2 - 4 } & Individual & Dual & Team \\
\hline $\begin{array}{c}\text { Planned Curriculum for } \\
\text { Sports }\end{array}$ & 0.245 & 0.229 & 0.258 \\
\hline $\begin{array}{c}\text { Admission/Retention } \\
\text { Policies for Sports }\end{array}$ & 0.192 & -.0245 & 0.163 \\
\hline Student Support & -0.125 & 0.139 & -0.346 \\
\hline School Sports Facilities & $0.028^{*}$ & $0.011^{*}$ & $0.015^{*}$ \\
\hline Manpower Resources & $0.013^{*}$ & $0.022^{*}$ & $0.019^{*}$ \\
\hline Instructional Resources & 0.142 & 0.254 & 0.176 \\
\hline
\end{tabular}

**. Correlation is significant at the $\mathrm{p}<0.01$ level (2-tailed).

*.Correlation is significant at the $\mathrm{p}<0.05$ level (1-tailed).

Table 4 presents the relationship between the special program in sports implementation and student-athletes performance in sports competitions. Based on the results, among the categories of a special program in sports, sports facilities and manpower resources have been found to have significant relationships with student-athletes performance in terms of individual, dual, and team sports. However, categories such as planned curriculum, admission/retention policies, student supports, and instructional resources did not significantly correlate with student-athletes performance.

Sports facilities and manpower resources such as coaches and teachers most likely to be an integral part which compliments student-athletes performance. As noted by Sanni, Fashina, and Ede [16], adequate sporting activities, facilities and equipment can help and enhance sports development in the school. Smith and Smoll [17], argue that coaches play a significant role in the athletic environment, and their behaviors influence the technical, cognitive, strategic, and psychosocial developments of athletes and outcomes of sports participation. Thus, human resources and sports facilities could contribute in such a way to student-athletes performance. Therefore, the null hypothesis stating that there is no significant relationship between the extent of implementation of special program in sports and student-athletes performance is hereby rejected.

\section{Conclusions}

Based on the results, it indicated that implementation of a special program in sports was perceived as highly sufficient in terms of planned curriculum for sports, admission/retention policies, student support, manpower resources, and instructional resources. High sufficiency in these areas could be attributed to the proper application and enactment of provisions in the program implementation which are requisites to attain the curricular program objectives. On the other hand, schools' sports facilities were perceived as moderately sufficient since acquiring sports facilities and equipment required huge budget allocation.

Student-athletes performance in individual, dual, and team sports indicated would be dependent on the notion that the higher level of the competition they compete, the lower sports performance they manifest. Winning at a higher level of competition becomes tougher which is a normal scenario in national level since all competing athletes are already winners in their respective localities.

Furthermore, sports facilities and manpower resources have been found to have a significant relationship with student-athletes performance. Thus, both play significant roles that complement student-athletes productivity in sports.

\section{Recommendation}

Implementation in a special program in sports categories such as sports facilities and human resources 
had been found to have significant relationship with student-athletes performance, it is suggested that School heads and sports managers must consider providing adequate sports facilities and equipment to coaches and student-athletes since their performance in sports would be dependent on these essential provisions. Furthermore, school heads must also properly align teachers in assigning designations as coaches. More so, proving sufficient training and development would be deemed necessary for coaches to enhance human resources.

\section{Acknowledgements}

No external financial support was received for this study. The authors would like to thank all the respondents who participated in this study.

\section{REFERENCES}

[1] DepEd, "Implementing Guidelines on the Special Program in Sports.pdf.” p. 8, 2015, [Online]. Available: https://www.deped.gov.ph/2015/06/23/do-25-s-2015-imple menting-guidelines-on-the-special-program-in-sports-sps/.

[2] R. S. Mcgowen, "The Impact of School Facilities on Student Achievement, Attendance, Behavior, Completion Rate and Teacher Turnover Rate in Selected Texas High Schools,” Educ. Adm., vol. 47, no. 3, pp. 1-151, 2007, [Online].

Available: http://www.ccsenet.org/journal/index.php/ies/article/view/ 56005 .

[3] S. Ball, "Contributions Series Evaluating Educational Programs Evaluating Educational Programs,” ETS Sci. Policy Contrib. Ser., no. April, 2011.

[4] F. V Javier, “Assessing an Asian University's Organizational Effectiveness Using the Malcolm Baldridge Model,” Asian J. Bus. Gov., vol. 2, no. 1, pp. 37-55, 2012, doi: 10.7828/ajobg.v2i1.110.

[5] J. Bangsbo, "Performance in sports - With specific emphasis on the effect of intensified training," Scand. J. Med. Sci. Sport., vol. 25, no. c, pp. 88-99, 2015, doi: 10.1111/sms.12605.

[6] R. D. Pestano, "Kinestetik: Jurnal Ilmiah Pendidikan Jasmani SPORTS- TEACHERS, COACHING STYLE, BEHAVIOR, COMPETENCY AND
STUDENT-ATHLETES PERFORMANCE IN SPORTS,” vol. 5, no. 1, 2021.

[7] R. Bustamante, "How to Prepare Modern Specialist in the Sphere of Physical Culture and Sports? Implementation of the Special Program for Sports in Educational Programs”. International Journal of Environmental and Science Education, 11 (9) pp.3089-3099, 2016.

[8] A.S. Mercado, "Evaluation of the Physical Education and Sports Curriculum in various satellite campuses of Bicol State University. Educational Research and Reviews, 12 (16) pp811-816, 2017.

[9] M. Onofre and A. Marques, "Physical education and sport in the Philippines: From individual reality to collective desirability”. International Journal of Physical Education, 49 (3), pp.17-30

[10] K. Hardman, "The situation of physical education in schools: A European perspective”. Humanities Movement Journal, 9 (1), pp.5 2018.

[11] H. R. Bernard, Research in Anthropology, Fourth Edi. 2006.

[12] S. Toktas and M. Bas, "Investigation of the relationship between the self-confidence and motivation of high school students participating school sport contests," Univers. J. Educ. Res., vol. 7, no. 2, pp. 472-479, 2019, doi: 10.13189/ujer.2019.070220.

[13] E. Gencer and A. Öztürk, "The Relationship Between the Sport-Confidence and the Coach-Athlete Relationship in Student-Athletes,” J. Educ. Train. Stud., vol. 6, no. 10, p. 7, 2018, doi: 10.11114/jets.v6i10.3388.

[14] F. Moen and R. A. Federici, "Coaches' Coaching Competence in Relation to Athletes' Perceived Progress in Elite Sport,” J. Educ. Learn., vol. 2, no. 1, pp. 240-252, 2013, doi: 10.5539/jel.v2n1p240.

[15] NEW JERSEY COMPREHENSIVE HEALTH EDUCATION AND PHYSICAL EDUCATION CURRICULUM FRAMEWORK, "Instructional Resources,”.

[16] D. M. Sanni, C. Ede, and A. A. Fashina, "A study on the effects of inadequate sport equipment and facilities on sports development and academic performance in primary schools: a case study of Bwari area council of Abuja-Nigeria Dahiru," SPC J. Educ., vol. 1, no. 1, pp. 48, 2018, doi: 10.14419/je.v1i1.13946.

[17] R. E. Smith, "Coaching Behavior and Effectiveness in Sport and Exercise Measurement and Correlates of Coaching Behaviors Social-Cognitive Learning Theory: The Mediational Model,” no. November, pp. 1-25, 2020, doi: https://doi.org/10.1093/acrefore/9780190236557.013.188. 